\title{
Effective interventions and strategies for improving early child development
}

\author{
Inve in early child development is a smart and essential strategy for building \\ hunn crosesnata \\ Bernadette Daelmans and colleagues
}

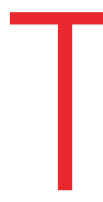

he millennium development goal on child health has led to great improvements in child survival worldwide. Child mortality has fallen by almost $50 \%$, resulting in an estimated 17000 fewer children dying every day in 2013 than in $1990 .{ }^{1}$ Nevertheless, many children who survive do not thrive, with over 200 million children under 5 years of age at risk of not attaining their developmental potential. ${ }^{2}$ Physical and mental health, educational and occupational attainment, family wellbeing, and the capacity for mutually rewarding social relationships all have their roots in early childhood. We now have a good understanding of the serious implications of young children going off course, including the longer term economic and societal ramifications. Here, we synthesise evidence about effective interventions and strategies to improve early child development, and call for it to be included in a new global strategy on women's, children's, and adolescents' health.

\section{Methods}

Our analysis draws on the following evidence: WHO records on early child development, beginning with the Commission on Maternal Care and Mental Health led by John

\footnotetext{
KEY MESSAGES

Adverse exposures and experiences in early childhood increase risks for poor social, cognitive, and health outcomes

Despite great strides in improving child survival over 200 million children under 5 are at risk of not reaching their full potential

Interventions implemented through health, nutrition, education, and social protection sectors are effective at improving early child development Such interventions have long term health, economic, and social benefits

Interventions to promote nurturing care, protect maternal mental health, and reduce poverty should be prioritised to complement and enhance services for maternal and child health and nutrition
}

Bowlby in $1951^{3}$; four special scientific journal issues on early child development and on efficacy and effectiveness of interventions and programmes ${ }^{2-6}$; the conclusions of the Commission on Social Determinants of Health $^{7}$; the WHO expert meeting held in January 2013 to review evidence on the role of the health sector in improving early child development ${ }^{8}$; and empirical neuroscience research linking early experiences with health and diseases across the lifespan.

\section{Why early development is important}

Child development refers to the expansion of physical, cognitive, psychological, and socioemotional skills that lead to increased competence, autonomy, and independence. What children experience during the early years (prenatal to the age of 5 years) creates a trajectory across the lifespan. Adverse exposures and experiences in early childhood increase the risk of poor social, cognitive, and health outcomes, including economic dependency, violence, crime, substance misuse, and adult onset of non-communicable diseases. Early deficits are compounded and become increasingly difficult to reverse beyond early childhood. ${ }^{9}$

Genes and experiences interact to shape brain architecture and functioning, which develops rapidly in the first few years of life when neuroplasticity is greatest. Neural connections formed early in life lay the foundations for physical and mental health, affecting adaptability, learning capacity, longevity, and resilience. ${ }^{10}$ Supporting children's development is therefore imperative, especially for the millions of children who live in disadvantaged and vulnerable families and communities and who face multiple adversities.

The figure summarises the risk factors for suboptimal development. They include biological and contextual factors. ${ }^{11}$ Gender disparities, for example, are a critical component of the sustainable development framework and start prenatally, with boys being more sensitive to neurological threats ${ }^{12}$ while girls are more at risk from selective abortion. ${ }^{13}$ To prevent and mitigate risks, integrated responses are required that improve children's physical, familial, and societal environments.

\section{Priorities for intervention}

Interventions to protect and support early child development start before conception and continue through pregnancy and childbirth into early childhood (box). ${ }^{14}$ Protecting children from illness and ensuring adequate nutrition are essential but not sufficient. Children need to grow in a caring, safe, and stimulating environment that provides opportunities for ongoing learning and mastery. We highlight three areas of intervention that can be integrated into ongoing programmes for maternal and child healthcare and nutrition: promotion of responsive and nurturing caregiving, supporting maternal mental health, and social protection through poverty reduction strategies that strengthen family capacity to provide for children.

The benefits of these interventions include better mental and physical health and academic performance during childhood and adolescence, and increased economic productivity and social integration during adulthood. ${ }^{15} 16$ The rate of return on investment in programmes that promote early childhood for disadvantaged children is estimated to be $7-10 \% .{ }^{17}$

\section{Promoting responsive and nurturing care} Children thrive in stable and engaged family environments in which parents show interest and encourage children's development and learning. WHO and Unicef developed Care for Child Development (CCD), an evidence based intervention to support care giving. ${ }^{18}$ By promoting age appropriate play and communication, CCD enables carers to strengthen their sensitivity and responsiveness to their child's needs. Responsive care giving in turn has an effect on care practices, including responsive feeding, seeking care for illness, child stimulation, and opportunities for learning, and it also benefits parental mental health. ${ }^{19}$ CCD has been shown to improve children's cognitive, social, and language scores. ${ }^{20}$ Landmark programmes, such the Jamaican home stimulation programme, have shown the immediate and long term effects of the intervention when delivered as part of health and nutrition services. $^{21}$ 


\section{ESSENTIAL INTERVENTIONS TO SUPPORT EARLY CHILD DEVELOPMENT}

\section{Preconception care}

- Promotion of adequate maternal nutrition

- Maternal immunisation

- Birth spacing

- Cessation of smoking and substance misuse

- Detection of genetic conditions

- Prevention from environmental toxins

- Prevention of intimate partnerviolence

- Support for mental health

Maternal health

- Antenatal, childbirth, and postnatal care by a skilled provider

- Detection and care for maternal mental health problems

Child health

- Immunisation

- Prevention and integrated management of newborn conditions

- Prevention and integrated management of childhood illnesses

- Counselling on Care for Child Development

Nutrition

- Counselling on infant and young child feeding, management of feeding difficulties, and inadequate growth

- Counselling on Care for Child Development

Adolescent health

- Promoting health literacy and support for healthy lifestyles

- Addressing adolescent health needs and agency for decision making to promote health and development

\section{Violence prevention}

- Prevention of child maltreatment

- Prevention of violence in the home and community

Environmental health

- Access to safe water, sanitation, and hygiene

- Access to electricity

- Safe places for play

- Prevention of exposure to toxins such as lead, mercury, and pesticides

- Prevention of indoor and outdoor air pollution

Social protection

- Social help and cash transfer schemes

- Birth registration

- Parental leave and child care

- Child protection services

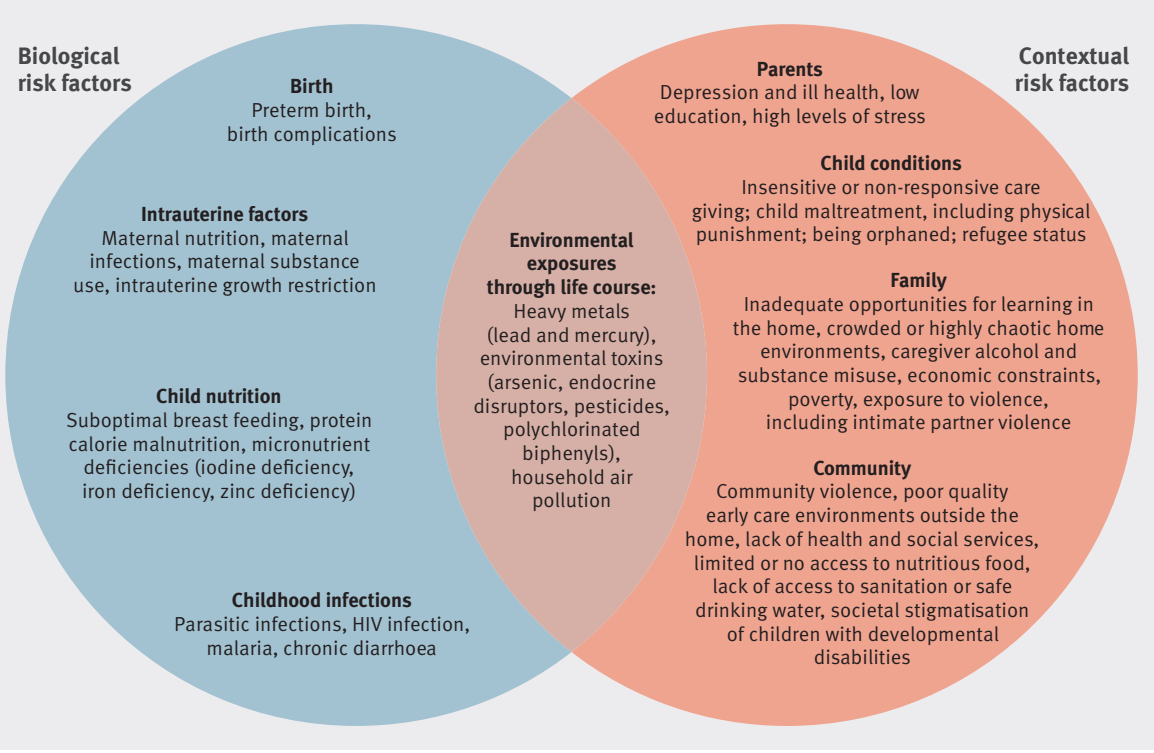

Factors compromising early child development
CCD can be integrated into services for well and sick children, preschool programmes, and services to prevent and manage maltreatment. ${ }^{22}{ }^{23}$ Work is in progress to develop complementary tools that enable providers to recognise when children show a developmental delay or disability and to act appropriately, with intensified intervention or referral. ${ }^{24}$ This addition is expected to improve the capacity of countries to care for children with disabilities and implement rehabilitative strategies. ${ }^{25}$

\section{Supporting maternal mental health}

Starting with Bowlby's seminal work on attachment and loss, ${ }^{3}$ evidence has accumulated about the adverse effects of maternal depressive symptoms on early child development and quality of parenting. Between a third and a fifth of pregnant women and mothers of newborns experience serious mental health problems that can be recognised through use of simple reliable tools. ${ }^{26}$ Poor maternal mental health nonetheless remains a seriously under-recognised public health problem. Young children can be protected against ill effects if mothers are helped to improve their caregiving skills and treated for their underlying conditions, as needed. ${ }^{27}$ These interventions can be integrated into health services and implemented by paraprofessionals through home visiting, mothers' groups, or by community health workers with specialised training.

\section{Family support through social protection to reduce poverty}

Poverty remains a pervasive determinant of suboptimal health and development. Children growing up in poverty have an increased likelihood of being exposed to environmental risks, household stresses, and violence; they also receive less optimal healthcare, nutrition, and education. Evidence from countries that have implemented large scale early child development programmes shows the importance of coordinated actions providing social protection (such as financial support); building parents' capacities (vocational training, parenting skills, etc), and using multiple platforms to reach families and children with effective interventions for health, nutrition, child care, and learning. ${ }^{28}$

Conditional cash transfer (CCT) programmes, implemented particularly in Latin America, and unconditional cash transfer programmes in sub-Saharan Africa have been shown to benefit nutrition and child development, helping to break the intergenerational effects of poverty. ${ }^{29}{ }^{30}$ By increasing household resources and access to early child care and preprimary education, such 
programmes can substantially boost children's learning and development.

\section{Moving forward}

Implementation of interventions to optimise child development need guidance and political will to promote coordinated governance, increased funding and capacity, and improved data collection to inform programme improvements and show that they work.

Coordinated governance-Leadership across sectors is needed at national, subnational, and local levels to implement coordinated interventions for young children and families. Coordinated governance must bring together health, nutrition, environment, education, and child and social protection, as well as the public and private sectors and civil society. ${ }^{31}$

Financing-Early childhood programmes and systems of support have been seriously underfunded. The establishment of coordinated early childhood plans should be a call to action to bilateral and multilateral agencies, national governments, and the private sector to dedicate increased funding through traditional and innovative financial instruments. ${ }^{32}$ Investment is also needed across multiple sectors to strengthen the capacity of the workforce, assure quality of services, and provide administrative oversight and accountability. Using multiple delivery platforms, such as community health workers, primary healthcare services, preschool education, and parent groups, is necessary to ensure success.

Improved measurement, research, and innovation-UN agencies are working together to develop and align new measures to track child development and monitor the quality of services and to use the results of evaluation to consolidate, extend, and improve programmes. New investments, methodological advancements, and political will are needed to validate these emerging measures, integrate them into existing data collection efforts, and help build management information systems that will generate data to guide policy. Although measurement has been a challenging issue in advancing early child development, there is now a selection of tools for assessing preschool children, including the Inter-American Development Bank's Regional Project on Child Development Indicators (PRIDI), the Early Development Instrument (EDI), and Save the Children's International Development and Early Learning Assessment (IDELA); scales are also emerging for children under 2 years old. ${ }^{33}$

Scientific, technological, social, and business innovation can ensure that the largest numbers of children are reached and that every child has support to reach their developmental potential. Innovations that promote healthy development in the first five years are showing the long term effect of early life interventions on physical, cognitive, and socioemotional development. They include mobile and internet based technologies to transfer information, financial assistance, and provision of home-based counselling and support by community workers. ${ }^{34}$

\section{Conclusions}

The new sustainable development goals adopted by the United Nations launch an exciting period in the global effort to end poverty, transform the world to better meet human needs, and protect the environment to ensure peace and realise human rights. As the recent secretary general report emphasises, "Millions of people, particularly women and children, have been left behind in the unfinished work of the MDGs [millennium development goals]." ${ }^{35}$ The new agenda can transform the way health and human services are delivered and create the conditions globally so children can have equitable opportunities to meet their developmental potential and grow into healthy and socially integrated citizens. This historic moment calls for a bold commitment to support healthy child development as the foundation for sustainable societies.

We thank Mark Tomlinson for a careful review of the draft manuscript.

Contributors and sources: This manuscript was developed as a background document to inform the content of a new Global Strategy for Women's, Children's and Adolescents' Health. The authors are members of the Steering Team on Early Child Development that is synthesising state-of-the art evidence on the burden of sub-optimal development

effective interventions, and programming at scale for early child development. BD coordinated the overall preparation of the manuscript. BD, MB, JL, JL, LR and KS prepared the first draft of the manuscript. All authors reviewed and contributed to the finalisation of the manuscript.

Competing interests: We have read and understood BMJ policy on declaration of interests and have no relevant interests to declare.

The authors alone are responsible for the views expressed in this article, which does not necessarily represent the views, decisions, or policies of WHO or the institutions with which the authors are affiliated.

Provenance and peer review: Not commissioned externally peer reviewed.

Bernadette Daelmans coordinator of policy, planning, and programmes ${ }^{1}$

Maureen M Black endowed professor of pediatrics ${ }^{2}$ Joan Lombardi senior adviser ${ }^{3}$

Jane Lucas consultant in early child development ${ }^{4}$ Linda Richter director distinguished research fellow ${ }^{5,6}$ Karlee Silver vice president programmes ${ }^{7}$

Pia Britto chief of early child development ${ }^{8}$

Hirokazu Yoshikawa professor of globalization and education ${ }^{9}$

Rafael Perez-Escamilla professor of epidemiology and public health ${ }^{10}$

Harriet MacMillan professor of psychiatry and

behavioural neurosciences ${ }^{11}$
Tarun Dua medical officer ${ }^{12}$

Raschida R Bouhouch technical officer Zulfiqar A Bhutta director ${ }^{13,14}$

Gary L Darmstadt associate dean for maternal and child health professor of neonatal and developmental pediatrics $^{15}$

Nirmala Rao professor of early childhood development and education ${ }^{16}$

1Department of Maternal, Newborn, Child, and Adolescent Health, World Health Organization, 1211 Geneva 27, Switzerland

2Department of Pediatrics, University of Maryland School of Medicine, Baltimore, Maryland, USA

${ }^{3}$ Bernard van Leer Foundation, The Hague, Netherlands ${ }^{4}$ New York, USA

${ }^{5}$ DST_NRF Centre of Excellence in Human Development, Durban, South Africa

${ }^{6}$ Human Sciences Research Council, Durban, South Africa

${ }^{7}$ Grand Challenges Canada, Toronto, Canada \&United Nations Children's Fund, New York, USA 9Department of Applied Psychology, NYU Steinhardt, New York, USA

${ }^{10}$ Department of Chronic Disease Epidemiology, Yale School of Public Health, New Haven, CT, USA

${ }^{11}$ Departments of Psychiatry and Behavioural Neurosciences and Pediatrics, McMaster University, Hamilton, ON, Canada

${ }^{12}$ Department of Mental Health and Substance Abuse, World Health Organization, Geneva, Switzerland

${ }^{13}$ Center for Global Child Health, Hospital for Sick Children, Toronto, Canada

${ }^{14}$ Center of Excellence in Women and Child Health, Aga Khan University, Karachi, Pakistan

${ }^{15}$ Department of Pediatrics, Stanford University School o Medicine, Stanford, CA, USA

${ }^{16}$ Faculty of Education, University of Hong Kong, China On behalf of the steering committee of a new scientific series on early child development.

Correspondence to: B Daelmans daelmansb@who.int (c) World Health Organization 2015. Licensee BMJ

This is an open access article distributed under the terms of the Creative Commons Attribution-

Noncommercial IGO License (https://creativecommons. org/licenses/by-nc/3.0/igo/), which permits use, distribution, and reproduction for non-commercial purposes in any medium, provided the original work is properly cited. In any reproduction of this article there should not be any suggestion that WHO or this article endorse any specific organisation or products. The use of the WHO logo is not permitted. This notice should be preserved along with the article's original URL.

WHO. Global health observatory. 2014. www.who. int/gho/child_health/mortality/mortality_under_ five text/en/.

2 Grantham-McGregor S, Cheung YB, Cueto S, et al. Developmental potential in the first 5 years for children in developing countries. Lancet 2007;369:60-70.

Bowlby J. Maternal care and mental health. Bull World Health Organ 1951;3:355-533.

4 Walker SP, Wachs TD, Grantham-McGregor S, et al. Inequality in early childhood: risk and protective factors for early child development. Lancet 2011;378:1325-38.

5 Black MM, Dewey KG. Promoting equity through integrated early child development and nutrition interventions. Ann N Y Acad Sci 2014:1308:1-10.

6 Britto PR, Engle PL, Super CM. Handbook of early childhood development research and its impact on global policy. Oxford University Press, 2013. Irwin LG, Siddiqi A, Hertzman C. Early child development: a powerful equalizer. Final report to the WHO Commission on Social Determinants of Health. WHO, 2007.

8 WHO. Meeting report: nurturing human capital along the life course: investing in early child development. WHO, 2013. 
9 Shonkoff JP, Phillips DA. From neurons to neighborhoods: the science of early childhood development. ERIC, 2000.

10 Shonkoff JP, Richter $L$. The powerful reach of early childhood development: a science-based foundation for sound investment. In: Handbook of early childhood development research and its impact on global policy. Oxford University Press, 2013:24-34

11 Wachs TD, Rahman A. The impact of risk and protective influences on children's development in low income countries. In: Handbook of early childhood development research and its impact on global policy. Oxford University Press, 2013:85-122.

12 Kent AL, Wright IM, Abdel-Latif ME. Mortality and adverse neurologic outcomes are greater in preterm male infants. Pediatrics 2012:129:124-31.

13 Richards E, Theobald S, George A, et al. Going beyond the surface: gendered intra-household bargaining as a social determinant of child health and nutrition in low and middle income countries. Soc Sci Med 2013;95:24-33

14 Denboba AD, Sayre RK, Wodon QT, Elder LK, Rawlings LB, Lombardi J. Stepping up early childhood development: investing in young children for high returns. World Bank, 2014

15 Gertler P, Heckman J, Pinto R, et al. Labor market returns to an early childhood stimulation intervention in Jamaica. Science 2014;344:998-1001.

16 Grantham-MCGregor SM, Fernald LC, Kagawa RM, Walker S. Effects of integrated child development and nutrition interventions on child development and nutritional status. Ann N Y Acad SC 2014;1308:11-32

17 Heckman J. Four big benefits of investing in early childhood development. 2015. http:// heckmanequation.org/content/ resource/4-big-benefits-investing-early-childhooddevelopment.
18 WHO, Unicef. Care for child development. 2012. www. who.int/maternal_child_adolescent/documents/ care child development/en/.

19 Yousafzai AK, Rasheed MA, Rizvi A, Armstrong R, Bhutta ZA. Effect of integrated responsive stimulation and nutrition interventions in the lady health worker programme in Pakistan on child development, growth, and health outcomes: a cluster randomised factorial effectiveness trial. Lancet 2014;384:1282-93.

20 Jin X, Sun Y, Jiang F, et al. Care for development intervention in rural China: a prospective follow-up study. I Dev Behav Pediatr 2007;28:123-8.

21 Grantham-McGregor SM, Powell CA, Walker SP, Himes JH. Nutritional supplementation, psychosocial stimulation, and mental development of stunted children: the Jamaican Study. Lancet 1991;338:1-5.

22 Sandler I, Schoenfelder E, Wolchik S, MacKinnon D. Long term impact of prevention programs to promote effective parenting: lasting effects but uncertain processes. Annu Rev Psychol 2011;62:299-329.

23 Mikton C, Butchart A. Child maltreatment prevention: a systematic review of reviews. Bull World Health Organ 2009;87:353-61.

24 Ertem I. Developmental difficulties in early childhood prevention, early identification, assessment and intervention in low- and middle-income countries: a review. WHO, 2012

25 Yousafzai AK, Lynch P, Gladstone M. Moving beyond prevalence studies: screening and interventions for children with disabilities in low-income and middle-income countries. Arch Dis Child 2014:99:840-8.

26 WHO. Maternal mental health and child health and development in low and middle income countries: report of the meeting, WHO, 2008

27 Rahman A, Malik A, Sikander S, Roberts C, Creed F. Cognitive behaviour therapy-based intervention by community health workers for mothers with depression and their infants in rural Pakistan: a cluster-randomised controlled trial. Lancet 2008:372:902-9.
28 Jayaratne K, Kelaher M, Dunt D. Child health partnerships: a review of program characteristics, outcomes and their relationship. BMC Health Serv Res 2010;10:172.

29 Garcia M, Moore CG, Moore CM. The cash dividend: the rise of cash transfer programs in sub-Saharan Africa: World Bank, 2012

30 Fernald LC, Gertler PJ, Neufeld LM. Role of cash in conditional cash transfer programmes for child health, growth, and development: an analysis of Mexico's Oportunidades. Lancet 2008;371:828-37.

31 Britto PR, Yoshikawa H, van Ravens I, et al. Strengthening systems for integrated early childhood development services: a cross-national analysis of governance. Ann N Y Acad SCi 2014:1308:245-55

32 UN Sustainable Development Solutions Network. Key elements for a successful Addis Ababa Accord on financing for sustainable development. UN, 2015.

33 Khan NZ, Muslima H, Shilpi AB, et al. Validation of a home-based neurodevelopmental screening tool for under 2-year-old children in Bangladesh. Child Care Health Dev 2013;39:643-50.

34 Pallas SW, Minhas D, Pérez-Escamilla R, et al. Community health workers in low- and middleincome countries: what do we know about scaling up and sustainability? Am J Public Health 2013;103:e74-82.

35 Moon B. The road to dignity by 2030: ending poverty, transforming all lives and protecting the planet. Synthesis report of the secretary-general on the post-2015 sustainable development agenda. UN, 2014.

Cite this as: $B M J$ 2015;351:h4029 